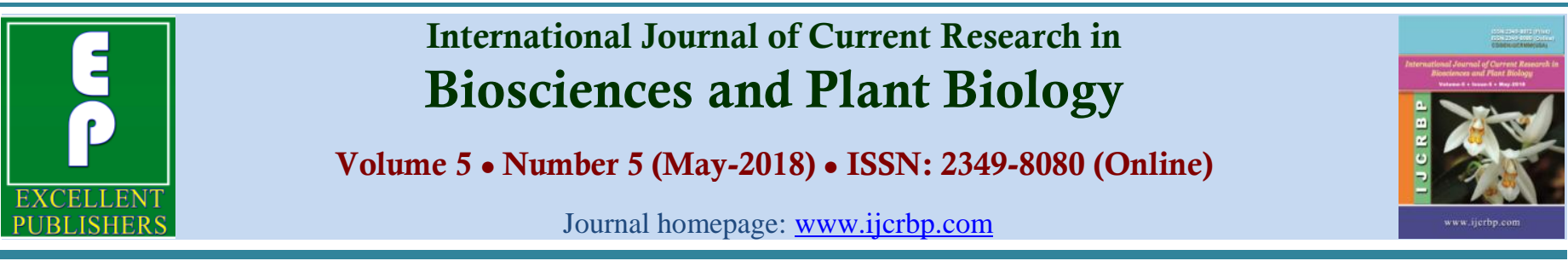

\title{
Analysis of Pesticide Residues in Agricultural Soil Using Thin Layer Chromatrography Techniques
}

\author{
Jimoh M. Abidun', Oyewole O. Nather ${ }^{2}$, Falodun A. Emmanuel2* and \\ Atere $\mathrm{O}$ Juliet $^{1}$
}

${ }^{1}$ Department of Art and Social Science Education, University of Ibadan, Nigeria

${ }^{2}$ Department of Science and Technology, The Federal Polytechnic, Ado Ekiti, Nigeria

*Corresponding author.

\begin{tabular}{|c|c|}
\hline Article Info & ABSTRACT \\
\hline Date of Acceptance: & \multirow{5}{*}{$\begin{array}{l}\text { This study investigated the level of pesticide residues in agricultural soil from three } \\
\text { locations around the southern part of Nigeria namely the cocoa plantations of Alade } \\
\text { Idanre, Owena and Saki area of Oyo State, Nigeria. Thin layer chromatographic } \\
\text { analysis was carried out on the sample and the standards after extracted with acetone } \\
\text { using Soxhlet apparatus. The } \mathrm{R}_{\mathrm{f}} \text { values of the soil extracted were compared with that of } \\
\text { the standard for quantitative identification of the pesticides. The soil samples were } \\
\text { weakly acidic and the } \mathrm{pH} \text { ranged from } 5.6 \text { to } 6.6 \text {. }\end{array}$} \\
\hline & \\
\hline $\begin{array}{l}\text { Date of Publication: } \\
06 \text { May } 2018\end{array}$ & \\
\hline Keywords & \\
\hline $\begin{array}{l}\text { Agricultural soil } \\
\text { Pesticides analysis }\end{array}$ & \\
\hline
\end{tabular}

\section{Introduction}

It is that fraction of a pesticide which as a result of its practical application has found its way into the produce or soil and is present there in the form of a parent compound or significant degradation products. Thus the term residues include any derivatives of a pesticide such as conversation products metabolites and impurities considered to be of toxicological significant. Apart from those streamlining from direct application to the above ground and underground part of the crop, residues also include those from unknown source such as contaminated water and air pollution (McEwen and Stepheson, 1979). Intensive agricultural practices often include the use of pesticide to enhance crop yield, however the improvement in yield is sometime concomitant with the occurrence and persistence of pesticide residues in the soil and water (Ware and Whitacre, 2004).

Pesticides are agents capable of destroying or inhibiting organisms. They include insecticides, fungicides, herbicides, etc. Most pesticides degrade fairly quickly on the crop and in the soil, but some may persist in one form or another for longer period of time. When they are used as recommended, pesticide are normally applied at only very low rate, but even so, small amount may be found on or in the treated crop at harvest, these traces of actives 
ingredient and their breakdown product are generally known as residues (Gunther, 1964). The amount of residues present in crop at harvest time is usually below one ppm and the techniques used for their determinations are extremely sensitive and often capable of measuring amounts of the order of $0.01 \mathrm{ppm}$ or less (Steinheimer, 1993). Before a new pesticide is marketed the residues level in crops are measured. From knowledge of the crops that a man may consume, and the effect which processing, may have on the residues level, one can estimate the typical intake of the residue per person. One way, which is used to decide whether or not acceptable is to compare it with the acceptable daily intake. This has been defined by the united nation, world health organization and food and agriculture as the daily intake, which during an entire lifetime, appears to be without appreciable risk on the basis of the known fact at that time. It is expressed in milligram of the chemical per kilogram of the body weight (FAO, 1993). The use of pesticide has been on for decade in many developing countries such as Nigeria, pesticide usage have been in use for over four decade in food and agricultural production and health (Osibanjo and Adeyeye, 1977).

Pesticides play a great role in increasing agricultural production. It is however essential that the use of pesticide should be carefully monitored in order to obtain maximum benefit from their application. At the same time their possible hazardous effect on non - target organisms and the environment as a result of their application should be taken into consideration. Most pesticides used in Nigeria agriculture are imported. It has been shown that there has been a tremendous increased in the use of pesticide in Nigeria over the year (Gaston, 1989).

Table 1. The names, active ingredients and properties of some pesticides commonly used in Nigeria.

\begin{tabular}{llll}
\hline Pesticide group & Trade name & Active ingredient & Chemical group of A.I \\
\hline Insecticides & Acetellic & Pirimiphos-methyl & Organophosphate \\
Insecticides & Alamon & Heptachlor & Organophosphate \\
Insecticides & Aldrex & Aldrine & Aldrine \\
Insecticides & Cymbush & Cyperime & Synthetic pyrethroid \\
Insecticides & DDT & DDT & Organophosphate \\
Insecticides & Dimecron & Phosphamidon & Organophosphate \\
Herbicides & Herbicides atranes & Atrazine & Triazine derivatives \\
Herbicides & Basagran & Benthazone & Dithiocarbamate \\
Herbicides & Grammazone & Paraquat & Bipyridyl derivatives \\
Herbicides & Igran & Terbacil & Bipyridyl derivatives \\
Herbicides & Starn & Propaml & Triazine derivatives \\
\hline
\end{tabular}

Some of the report gathered about the usage of pesticide in Nigeria show that most of the kokotine sold during 1970/74 was consumed in the cocoa belt of Ondo and Ogun State then, meanwhile diedrex and vatox 85 were used extensively in the cotton zone of Kaduna. There was also an available data that suggest an increase in the on-farm demand for gammalin 20 from 91,000 liters in 1957/58 to 1,398,638 liters in 1973/74 representing an increase of 1,437 percent. There was also an estimated state to state increase in the agricultural consumption of some pesticide between 1982 and 1985 (Idachaba and Olayide, 1976). This study was aim at investigating claims that were related to pesticide usage versus environmental contamination studies conducted in different parts of the country.

\section{Materials and methods}

Chemicals: Acetone, bromine, diethylether and ethanol used in the study were of the highest purity commercially available.

\section{Study area}

The study area includes Ondo cocoa production region and food crop production region in Oyo state. These sites were Idanre (an older cocoa 
producing sites), Owena (an intermediate cocoa producing region and Saki (a food production area). A total of 15 soil samples were collected in this study area from the month of February to March 2006. Soil was collected from $5 \mathrm{~cm}$ beneath the soil surface using a field soil auger.

\section{Sample code}

Idr 001,Idr 002, idr 003, idr 004, idr 005, Own 006, Own 007, Own 008, Own 009, Own 0010, Sak 0011, Sak 0012, Sak 00`13, Sak 0014 and Sak 0015 were the codes of soil samples in the present study.

\section{Sample preparation and extraction}

The soil samples were dried at a temperature of $40^{\circ} \mathrm{C}$ in the oven to a constant weight. The sample weighing $20 \mathrm{~g}$ was put in an extraction thimble. The soil sample inside the thimble was moistened with 2 $\mathrm{cm}^{3}$ of distilled water and placed into Soxhlet extractor. The apparatus is fitted with $250 \mathrm{~cm}^{3}$ round bottom flask containing $100 \mathrm{~cm}^{3}$ of acetone solvent and reflux for 6hrs. The extract was dried and anhydrous sodium sulphate was added to remove water molecule and followed by filtration. Concentrated extract of each sample and standard solution $(1 \mathrm{mg} / \mathrm{ml})$ was spotted on $20 \times 20 \mathrm{~cm}^{3}$ precoated silicagel. TLC plate at the same time chromatograms were developed in a TLC chamber saturated with mixtures of diethyl ether and ethanol (85:15) as the mobile phase. After the mobile marked phase had traveled some distance the solvent front was marked, and the plate was removed from the chamber air dried until ethanol evaporated and subsequently kept for some periods in the chamber containing bromine vapours. The time taken for each development was noted. The $\mathrm{R}_{\mathrm{f}}$ value which is the retention factor were measured and calculated for each sample using the following expression.

$$
\mathrm{R}_{\mathrm{f}}=\frac{\text { Distance moved by solute front }}{\text { Distance moved by solvent front }}
$$

\section{Results and discussion}

The thin layer chromatographic results of sample extracts and standard with their class as well as the soil $\mathrm{PH}$ in the course of this investigation are presented in Tables 2-4.

Table 2. $\mathrm{R}_{\mathrm{f}}$ value of sample extracts and sample standard.

\begin{tabular}{llll}
\hline Sample & Active ingredients & Rf std & Rf sample \\
\hline 001 & Lindane & 0.46 & 0.46 \\
002 & Diazinon & 0.17 & 0.17 \\
003 & Propoxur & 0.52 & 0.52 \\
004 & Glyphorate & 0.51 & 0.51 \\
005 & Propoxur & 0.52 & 0.52 \\
006 & ND & ND & ND \\
007 & Paraquat & 0.29 & 0.29 \\
008 & ND & ND & ND \\
009 & Propoxur & 0.51 & 0.51 \\
010 & ND & ND & ND \\
011 & Carbufran & 0.40 & 0.40 \\
012 & Chorpyritos & 0.48 & 0.48 \\
013 & ND & ND & ND \\
014 & ND & ND & ND \\
015 & Cabuforan & 0.40 & 0.40 \\
\hline
\end{tabular}


Table 3. $R_{f}$ values of pesticide standard used and their class.

\begin{tabular}{lll}
\hline Pesticides & Class & RF values \\
\hline Chlorpyrifos & Organophosphorus & 0.48 \\
Diazinon & Organophosphorus & 0.17 \\
Glyphosate & Organophosphorus & 0.51 \\
Endosulfan & Organophosphorus & 0.22 \\
Lindane & Organophosphorus & 0.46 \\
Propoxur & Carbamate & 0.52 \\
Carbofuran & Carbamate & 0.40 \\
\hline
\end{tabular}

Table 4. $\mathrm{pH}$ of the soil samples.

\begin{tabular}{ll}
\hline Sample Code & Soil pH \\
\hline 001 & 6.3 \\
002 & 6.3 \\
003 & 6.3 \\
004 & 6.2 \\
005 & 5.6 \\
006 & 6.4 \\
007 & 6.3 \\
008 & 6.3 \\
009 & 6.3 \\
010 & 6.4 \\
011 & 6.5 \\
012 & 6.5 \\
013 & 6.2 \\
014 & 6.1 \\
015 & 6.2 \\
\hline $\mathrm{N}=$ fifteen samples analysed; ND= Not detected.
\end{tabular}

The result in Table 2 corresponds to the level of pesticides and active ingredients in the samples analysed. In all the fifteen samples analysed from these three areas, the active ingredients detected were lindane, diazinon, propoxur, glyphosate, paraquat, carboforan and chlorpyrifos during separation on a precoated silica gel developed with diethylether and ethanol. Their detections were with bromine vapour in a chamber qualitatively. The identification was based on the comparison of $R_{f}$ values of each standard and sample. The soil samples were weakly acidic and the $\mathrm{pH}$ range from $5.6-6.6$.

\section{Conclusion}

With regards to the result obtained, it is suggested that the use of pesticide should be rightfully controlled on all phases of the Nigerian environment to determine it desirability and users should be given adequate information on any brands of the pesticide in the country to minimize the problem of mishandling.

\section{Conflict of interest statement}

Authors declare that they have no conflict of interest.

\section{References}

FAO, 1983. Manual of Methods in Aquatic Environment Research. Food and Agriculture Organization of the United Nations, Rome.

Gaston, C.P.C., 1989. Environmental and agriculture region office for Asia and the Pacific FAO/RAPA

Gunther, F. A., 1964. Residues of pesticide and other foreign chemicals. In: Foods and Feed. Vol.6, pp.2-5.

Idachaba, F. S., Olayide, S.O., 1976. The Economics of pesticide use in Nigerian Agriculture. A report of study commissioned by the Federal Department of Agriculture.

Mc Ewen, F. L., Stepheson, G. R., 1979. The Use and Significant of Pesticide in the Environment. John Wiley and Sons, New York. 538p.

Osibanjo, O., Adeyeye, A., 1995. Organochlorine pesticide residuces in cereals in Nigeria market. 
Bull. Environ. Contam. Toxicol. 54, 460-465.

Steinheimer, T. R., 1993. HPLC determination of afrazine and principal degradates in agricultural soil and associated surface and ground water. $\mathrm{J}$.
Agric. Food Chem. 41, 588 - 595

Ware, G.W., Whitacre, D. M., 2004. The pesticide Book Meisterpro Information Resources. Williongby, Ohio. 496p.

\section{How to cite this article:}

Abidun, J. M., Nather, O. O., Emmanuel, F. A., Juliet, A. O., 2018. Analysis of pesticide residues in agricultural soil using thin layer chromatrography techniques. Int. J. Curr. Res. Biosci. Plant Biol. 5(5), 2529. doi: https://doi.org/10.20546/ijcrbp.2018.505.004 